\title{
Partner violence during pregnancy: prevalence, effects, screening, and management
}

\author{
This article was published in the following Dove Press journal: \\ International Journal of Women's Health \\ 24 June 2010 \\ Number of times this article has been viewed
}

\author{
Beth A Bailey \\ Department of Family Medicine, East \\ Tennessee State University, Johnson \\ City, TN, USA
}

\begin{abstract}
The purpose of this review is to provide an overview of the current state of knowledge regarding the experience of intimate partner violence (IPV) during pregnancy. Pregnancy IPV is a significant problem worldwide, with rates varying significantly by country and maternal risk factors. Pregnancy IPV is associated with adverse newborn outcomes, including low birth weight and preterm birth. Many mechanisms for how IPV may impact birth outcomes have been proposed and include direct health, mental health, and behavioral effects, which all may interact. Screening for IPV during pregnancy is essential, yet due to time constraints and few clear recommendations for assessment, many prenatal providers do not routinely inquire about IPV, or even believe they should. More training is needed to assist health care providers in identifying and managing pregnancy IPV, with additional research needed to inform effective interventions to reduce the rates of pregnancy IPV and resultant outcomes.
\end{abstract}

Keywords: intimate partner violence, pregnancy, pregnancy screening, pregnancy risks

\section{Introduction}

Intimate partner violence (IPV) is the currently accepted term used to describe what has been referred to as "woman abuse," "woman battering," or "domestic violence." IPV has been defined as "repeated physical and/or sexual assault by an intimate partner within the context of coercive control." ${ }^{1}$ While this definition recognizes the role of the intimate partner and the role of control, it excludes non-physical violence, an aspect of IPV often overlooked by health care providers and public health professionals. ${ }^{2}$ The US National Institutes of Mental Health Committee on Family Violence has proposed a broader description of IPV as "acts that are physically and emotionally harmful or that carry the potential to cause physical harm ... [and] may also include sexual coercion or assaults, physical intimidation, threats to kill or harm, restraint of normal activities or freedom, and denial of access to resources." ${ }^{3}$ This latter definition includes the three primary types of IPV recognized in the literature: physical, sexual, and emotional/ psychological/verbal violence. ${ }^{4}$ Intentional use of physical force is encompassed in "physical violence," and use of force to compel a person to engage in a sexual act is what is referred to as "sexual violence."5 "Emotional," "psychological," or "verbal" violence includes threats, humiliation, control of activities, isolation, name calling, and attempts to frighten. ${ }^{6}$

The purpose of this review is to provide an overview of the current state of knowledge regarding the experience of intimate partner violence during pregnancy. It is our hope that this paper will provide useful information for researchers, health care providers, and policy makers. Findings from research conducted in countries throughout the
Department of Family Medicine

East Tennessee State University,

PO Box 7062I, Johnson City,

TN 376 I4, USA

Tel + I 4234396477

Fax +I 4234392440

Email nordstro@etsu.edu 
world are described including information on the prevalence of pregnancy IPV, known effects, available screening methods, and management of this important health concern. The research reviewed was limited to English language reports. Preference was given to reports of large scale quantitative studies published in peer reviewed journals. However, some government reports were used, as were a few smaller scale and qualitative studies. This was necessary in order to provide the most accurate and up to date prevalence data and screening/ management recommendations, and to insure inclusion of information about pregnancy IPV in developing countries. As a result, however, conclusions drawn throughout this paper reflect the subjective interpretation of the author and the authors of other cited published papers. While a handful of systematic reviews of the literature have been published on various subtopics covered in this paper, a large scale comprehensive systematic review is still needed in order to draw specific and completely evidence-based conclusions formulated from comparisons of level of evidence and scientific rigor across available studies.

\section{Prevalence}

\section{General}

IPV is a significant medical, public health, and societal concern worldwide. ${ }^{7-9}$ Total annual health care costs related to IPV run into the billions in the United States, ${ }^{10,11}$ and IPV accounts for $20 \%$ of all violent crime. ${ }^{12}$ Twenty years ago, the US Surgeon General identified IPV as a public health problem of "epidemic" proportions. ${ }^{13}$ Reducing the rate of violence by current and former partners is one objective of the US Public Health Service's Healthy People 2010 initiative. ${ }^{14}$ This is not surprising when the prevalence of IPV is examined. The US Department of Justice estimates that over a lifetime, $52 \%$ of women experience IPV. ${ }^{15}$ In addition, $45 \%$ of those abused also report having been forced to have sex with their intimate partner. ${ }^{16}$ Anywhere from 1.5 to 4 million US women are victimized by an intimate partner each year. ${ }^{17,18}$ Studies of female patients seeking health care have reported prevalences of $19 \%-33 \%$ for physical or sexual abuse, ${ }^{19,20}$ and $19 \%-66 \%$ for any form of IPV. ${ }^{17,21,22}$ Indeed, IPV is the leading cause of injuries and death among US women of childbearing age. ${ }^{23}$

Data on prevalence rates of IPV in other countries are also available. In a 2005 national Australian population study, $15 \%$ of women reported having experienced physical or sexual abuse in an intimate relationship. ${ }^{24}$ A Canadian study conducted with female family practice patients revealed a current or recent rate of any type of IPV of $15 \%,{ }^{25}$ while a similar study in Spain found a 32\% lifetime prevalence of any type of IPV. ${ }^{26}$ In Ukraine, a national survey put the rate of ever experiencing any type of IPV in a current relationship at $20 \% .{ }^{27}$ A study of women seeking medical care in Rwanda revealed a life time prevalence of IPV at $35 \%,{ }^{28}$ while similar figures from Nicaragua range from $40 \%$ to $52 \% .{ }^{29}$ Finally, a study of women in Peru produced a lifetime IPV prevalence rate of $45 \%,{ }^{30}$ while $35 \%$ of women who participated in a national health survey in India reported ever having experienced IPV. ${ }^{31}$ Recent findings from ten countries with data collected using a standardized instrument revealed a physical or sexual IPV lifetime prevalence from $15 \%$ to $71 \%,{ }^{32}$ while a review of population-based studies around the world reported a 10\%-15\% lifetime physical IPV prevalence. ${ }^{33}$ Thus, it should not be surprising that one of the outcomes from the Fourth World Conference on Women (Beijing, 1995), was a call to encourage additional research on violence against women, including effective preventive measures, and an appeal to governmental and nongovernmental agencies to work to address IPV. ${ }^{34}$

\section{Pregnancy}

Researchers disagree about whether the prevalence of IPV decreases during pregnancy, remains about the same, or if a woman is at increased risk for IPV in the time between conception and delivery. Recent comprehensive reviews have generally concluded that while some hospital and clinic based studies noted an increased risk, national and international population-based studies have found either that pregnant women are no more likely than nonpregnant women to experience IPV, or may even be at decreased risk. ${ }^{35}$ Since research of violence during pregnancy currently accounts for $20 \%$ of all reviewed nursing research, ${ }^{36}$ differing prevalence estimates abound. Gazmararian et al in a comprehensive review of the literature, concluded that the prevalence of IPV in pregnancy ranged from $1 \%-20 \%$, depending on the way IPV is assessed and the population studied. ${ }^{7}$ Population based studies, including the US Centers for Disease Control and Prevention's (CDC) Pregnant Risk Assessment Monitoring System (PRAMS), which includes tens of thousands of women in 11 states, suggested the prevalence of pregnancy IPV is only $2.9 \%-5.7 \% .{ }^{37}$ Similarly, a population-based study in New Zealand revealed a prevalence of pregnancy IPV of $9 \%{ }^{38}$

The problem with population-based studies of IPV is that while large and representative, the way IPV is assessed may lead to an underestimate of those affected. For example, those who participated in PRAMS were asked only a few general 
questions about IPV. These questions were not behaviorally specific. In addition, the term "abused" was used, which may be regarded as demeaning or judgmental. ${ }^{39}$ Several projects have subsequently demonstrated that many women who claim they have not been "abused," on specific follow-up questioning admit to experiencing violence. ${ }^{40,41}$

Several smaller-scale studies that included behaviorally specific questions have suggested much higher prevalence rates of IPV during pregnancy. Two US projects that included the Abuse Assessment Screen (AAS), a behaviorally specific measure described below, revealed a $10 \%$ prevalence of physical abuse during pregnancy. ${ }^{42,43}$ Yet another study of low risk women from private obstetric practices in the US revealed $11 \%$ had experienced abuse during pregnancy. ${ }^{44} \mathrm{~A}$ study of over 1,000 prenatal patients at public clinics in the US revealed $15 \%$ were abused during pregnancy, ${ }^{45}$ as did a study of nearly 1,000 women seeking care in US family practice clinics who completed the AAS. ${ }^{46}$ Somewhat higher pregnancy IPV rates have been reported in Nicaragua, ${ }^{47}$ Turkey ${ }^{48}$ and Pakistan, ${ }^{49}$ while similar or slightly lower rates have been noted in India ${ }^{50}$ and Belgium. ${ }^{51}$

Several studies have included examination of prevalence rates of specific types of IPV. For example, $36 \%$ of patients at an obstetrics clinic in the US reported verbal abuse, $16 \%$ physical violence, and 14\% reported severe physical violence when completing a modified AAS during pregnancy. ${ }^{52}$ And in a US study that used an even more detailed and behaviorally specific tool (the Conflict Tactics Scale, also described below), an incredible $81 \%$ of prenatal patients at a family practice clinic reported some type of IPV during pregnancy; $28 \%$ reported physical IPV, and 20\% reported sexual violence. ${ }^{53}$ These final studies highlight that prevalence disparities may in some cases be related to the type of tool used, and whether abuse includes verbal as well as physical abuse, and may partly explain differences in rates reported across studies. Based on findings from research like that presented above, some researchers have estimated that every year in the US, over 300,000 pregnant women experience IPV. ${ }^{54,55}$

\section{Risk factors}

As high as these rates are, the actual prevalence of IPV during pregnancy may be even higher due to reluctance of women to disclose IPV, especially during pregnancy. ${ }^{56}$ In addition, many studies have indicated certain women may be at increased risk of IPV during pregnancy due to socioeconomic status (SES), age, marital status, or minority status. While IPV can be found at all SES levels, many studies identify increased risk of IPV among both pregnant and nonpregnant lower SES women. ${ }^{57,58}$ Population based studies also confirm the link between IPV and SES, ${ }^{59,60}$ as did analysis of the PRAMS data from pregnant women. ${ }^{61}$ A project involving $1000+$ pregnant women in the US revealed that income and education levels were the most significant predictors of pregnancy violence. ${ }^{62}$ Similarly, a population-based study conducted in Chile, Egypt, India, and the Philippines demonstrated that socioeconomic indicators were the most commonly and universally predictive factors of IPV. ${ }^{63}$

Younger women, those who are not married, and women from minority groups are also at increased risk for pregnancy IPV. Many reports have identified an association between younger age and pregnancy IPV, ${ }^{64,65}$ with those abused up to four years younger on average. ${ }^{66}$ Some national survey reports suggest a nearly double risk of pregnancy IPV for women under $20 .{ }^{67}$ Similarly, single women are at increased IPV risk during pregnancy compared with married women, ${ }^{66}$ with one study noting a fourfold increase in pregnancy IPV risk among single versus married women. ${ }^{67}$ Other characteristics associated with increased risk include racial and ethnic background, especially minority status. ${ }^{41,62,66}$ In the United States in particular, Native American and African American women have an especially increased incidence of pregnancy IPV. ${ }^{68,69}$ These many and varied factors that are associated with a statistically increased likelihood of pregnancy IPV may also help explain the differing prevalence estimates described above. Clearly, studies with samples that consist of a large percentage of women with these "higher risk" characteristics will produce higher prevalence estimates than those studies with lower risk samples.

It is clear, then, that a substantial proportion of women worldwide have been victimized by an intimate partner. Whether pregnancy is a protective factor is unclear, however, expectant women across various studies and settings have reported significant levels of IPV. Rates of pregnancy IPV appear to differ across countries, although comparative conclusions are difficult due to differences in study methodologies. However, we know that many more women will report abuse when questions about psychological victimization are included. Additionally, we know that while no groups of women can be considered immune from pregnancy IPV, certain characteristics are associated with an increased likelihood of this experience, and disproportionate inclusion of higher risk women in studies will increase reported prevalence rates. In particular, younger minority women at the lower socioeconomic levels and who are 
unmarried are more likely than other women to experience IPV while pregnant.

\section{Effects}

\section{Low birth weight and preterm delivery}

The experience of IPV during pregnancy is associated with numerous negative consequences, including decreased infant birth weight and increased rates of prematurity. Low birth weight (LBW) and preterm births are leading causes of neonatal morbidity and mortality. Babies born before 37 completed weeks gestation are classified as preterm, while infants born weighing $<2,500 \mathrm{~g}$ are termed LBW. Prematurity and LBW often coexist, however $40 \%$ of all LBW babies are born at 37 weeks or later. ${ }^{70}$ These full term babies are referred to as small-for-gestational-age (SGA). Premature and low birth weight infants consume disproportionate amounts of scarce health care resources, and for those babies who survive prematurity and low birth weight, adverse initial and long-term outcomes are common. In fact, an infant's gestational age (GA) and birth weight at delivery are the strongest biological predictors of immediate and long-term developmental outcomes. $^{71}$ Research documents the long-term sequelae of extremely premature and LBW infants. Such children commonly have cognitive deficits, motor delays including cerebral palsy, academic difficulties, language delays, and significantly increased rates of attention problems, behavioral difficulties, and psychological problems. ${ }^{72-74}$ But even children born at 32-36 weeks, or weighing 1,500-2,500 g, are at increased risk. ${ }^{75}$ Cognitive deficits, including neurological impairment, ${ }^{76}$ delayed mental development and decreased IQ,${ }^{77-79}$ memory problems, ${ }^{80}$ and increased need for special education services ${ }^{81}$ are common. Attention, behavior, and psychological problems have also been linked to prematurity, LBW, and SGA. ${ }^{79,82}$ Still other risks for preterm and LBW births are physical/biological, as several studies have documented permanent growth restriction for children born prematurely or with LBW. ${ }^{79,83}$ Further, poor general health well into childhood has been associated with SGA birth. ${ }^{84}$ Specific health risks including an increased risk of sudden infant death syndrome, ${ }^{85,86}$ and increased severity of respiratory synctial virus (RSV) infection for premature infants have been noted..$^{87,88}$

It is apparent, then, that many and varied adverse outcomes are associated with prematurity and LBW. Thus, that IPV during pregnancy might be linked to prematurity and LBW births is of great concern. Indeed, given such an association, it may be possible to reduce LBW and prematurity rates through interventions targeting IPV. ${ }^{89}$ Dozens of studies have now been published that included an examination of the relationship between IPV and prematurity and LBW. Generalizations across studies are difficult due to different populations, assessments, methods, and data analysis. However, over a dozen recent studies have identified significant associations. An analysis of the US PRAMS data revealed a significant link between physical abuse during pregnancy and LBW. ${ }^{61}$ Reports of two other smaller scale studies also include significant associations between physical IPV during pregnancy and low birth weight, ${ }^{90,91}$ with one including a mean difference in birth weight of 164 g. ${ }^{90}$ And in another study, compared with non-abused women, those abused had significantly increased rates of preterm deliveries (22\% vs $9 \%$ ) and LBW babies (16\% vs 6\%). ${ }^{92}$ Research with women in China, South Africa, and Saudi Arabia revealed similar findings. ${ }^{93-95}$

Still other studies found significant associations between pregnancy IPV and newborn outcomes, even after control for background and other factors associated with either IPV and/or newborn outcomes. For example, among over 400 low income women, any form of IPV during pregnancy was associated with a $250 \mathrm{~g}$ decrease in infant birth weight, and this link remained significant even after control for sociodemographic factors including prenatal care and stressors. ${ }^{96}$ Similarly, other studies have noted a two- to fourfold increase in the risk of LBW associated with pregnancy IPV after control for confounding. ${ }^{58,97}$ Using police reported, rather than self-reported IPV, significant negative associations between IPV and birth weight and gestational age at delivery were identified, even after control for sociodemographic factors, adequacy of prenatal care utilization, and prenatal smoking. ${ }^{98} \mathrm{~A}$ recent large-scale study revealed that physical injury due to IPV was associated with preterm birth and a $75 \mathrm{~g}$ reduction in birth weight, even after control for sociodemographics, prenatal substance use, pregnancy weight gain, and pregnancy complications. ${ }^{19}$ Interestingly, the authors report that when gestational age is controlled, the birth weight reduction is only $24 \mathrm{~g}$, suggesting that most of the association between IPV and birthweight can be explained by a decrease in gestational age. Finally, a meta-analysis of eight methodologically sound and recent studies revealed a significant association between pregnancy IPV of any kind and newborn outcomes (pooled odds ratio of 1.4 for birth weight). The authors of this review concluded that due to the recent findings from analyses that included control for a multitude of factors, a relationship between IPV and newborn outcomes indeed 
exists, but may be secondary to, or explained by, prenatal smoking, substance use, or inadequate pregnancy weight gain among other factors. ${ }^{89}$

\section{Mechanisms for effects}

So why might the experience of IPV lead to poor birth outcomes? Many factors may explain the association including direct physical effects, and the impact on mental health and behavioral changes. For example, abuse involving abdominal trauma can lead to premature labor, rupture of membranes, placental abruption, and ruptured uterus, all of which lead to preterm birth or even fetal demise. ${ }^{99-102}$ IPV has also been associated with an increased incidence of urinary tract infections which have been associated with preterm birth. ${ }^{103-105}$ Additionally, IPV during pregnancy may exacerbate chronic problems such as hypertension and gestational diabetes, both of which have implications for newborn outcomes. ${ }^{103,106}$ And finally, cervical and uterine infections, including HIV and other sexually transmitted diseases (STDs), occur at higher rates among abused pregnant women compared to those not abused, ${ }^{66,107}$ placing them at increased risk for intrauterine growth restriction and preterm birth. ${ }^{108-110}$

In addition to direct physical and health effects, pregnancy IPV has been associated with many mental health factors as well. ${ }^{11,112}$ Women who experience IPV either during or outside of pregnancy were found to have a ninefold increase in risk for a mood or anxiety disorder, ${ }^{113}$ to be significantly more likely to be hospitalized for mental health related problems,${ }^{98}$ and half of the women referred to a rural mental health center by their health care provider turned out to be unrecognized battered women. ${ }^{114}$ Experience of mental health problems during pregnancy has in turn been associated with adverse newborn outcomes. ${ }^{115}$ Depression has been identified as the most common mental health consequence of IPV, ${ }^{116}$ with nearly $40 \%$ of abused women reporting symptoms, ${ }^{117,118}$ and depression in pregnancy has been linked to both preterm birth and LBW. ${ }^{119-121}$ In addition, other studies have shown that $45 \%$ of women experiencing IPV were found to have posttraumatic stress disorder, ${ }^{118}$ with stress in pregnancy associated with both preterm birth and LBW in multiple projects. ${ }^{122-124}$ These findings have led researchers to conclude that further work is needed to understand the role of depression and stress in the relation between IPV and preterm and low birth weight births, ${ }^{125,126}$ so that clinical practice might be better informed and appropriate interventions can be designed. ${ }^{127}$

Besides the effects IPV may have on physical or mental health, IPV has also been associated with many negative health behaviors during pregnancy, perhaps stemming at least in part from the associated mental health effects as described above. These behaviors, including inadequate prenatal care utilization, inadequate weight gain, and smoking, drinking, and substance use during pregnancy, have in turn been associated with negative newborn outcomes. For example, one of the primary health behavior factors associated with both IPV and prematurity and LBW is inadequate prenatal care utilization. A link between IPV and late entry into prenatal care has been described in multiple reports, ${ }^{91,107,128}$ with those experiencing IPV twice as likely to begin care in the third trimester, ${ }^{65,129}$ and entering care up to 6.5 weeks later, ${ }^{130}$ compared with other women. Additionally, women experiencing pregnancy IPV are significantly more likely than non-abused women to miss three or more prenatal visits $(45 \%$ vs $28 \%){ }^{44}$

Much published research suggests inadequate prenatal care utilization is linked to poor neonatal outcomes. ${ }^{131}$ In particular, studies involving higher risk populations (minorities, teenagers, lower SES) have revealed significant relations between prenatal care (timing of entry, number of visits, and adequacy of care utilization) and both infant birth weight and prematurity. ${ }^{132-135}$ Even in low risk populations, a link between prenatal care rates and prematurity ${ }^{136}$ and $\mathrm{LBW}^{137}$ has been noted.

Poor nutritional intake and inadequate weight gain have also been associated with both pregnancy IPV and adverse newborn outcomes. Several reports detail an association between pregnancy IPV and failure to gain weight. ${ }^{97,138}$ In fact, one study noted that history of physical IPV increases the risk of inadequate prenatal weight gain threefold. ${ }^{139}$ Additionally, many studies have identified an association between inadequate pregnancy weight gain or poor nutrition and adverse outcomes, including LBW. ${ }^{140-142}$ A recent study found that the relation between pregnancy IPV and infant birth weight was completely mediated by poor pregnancy weight gain, ${ }^{143}$ and others have supported this contention. ${ }^{144}$

Smoking during pregnancy is another health factor linked to both IPV and newborn outcomes. Many studies have described an association between IPV and pregnancy smoking. ${ }^{45,66,107,138,145}$ Projects have reported that smoking partially mediates the association between IPV and poor newborn outcomes, ${ }^{143}$ possibly due to the association between smoking and stress and depression. ${ }^{115,126,143}$ As had been reviewed, ${ }^{146,147}$ prenatal cigarette exposure is associated with both LBW and prematurity. Dozens of studies have reported a link between prenatal cigarette exposure, and prematurity/LBW. ${ }^{148-151}$ Effects are not limited to those heavily exposed. National statistics for 2002 reveal that $11.5 \%$ of babies born to light 
smokers (fewer than six cigarettes/day) were LBW, more than $50 \%$ higher than the LBW rate for births to nonsmokers. ${ }^{145}$

Finally, alcohol and illicit substance use have also been implicated in the relationship between IPV and adverse newborn outcomes. Multiple projects have described an increased risk of alcohol and substance use among pregnant battered women. ${ }^{44,98,125,143}$ Indeed, up to $50 \%$ of alcoholism in women may be precipitated by abuse. ${ }^{152}$ Numerous studies have identified an association between prenatal alcohol and drug exposure and adverse newborn outcomes including prematurity and low birth weight. ${ }^{92,121,148,153-155}$

Clearly, the experience of IPV during pregnancy has many adverse consequences. Babies born to women who are subjected to IPV while pregnant have a significantly increased risk of being born preterm or LBW, which can result in immediate and long term health and developmental problems. Effects are not limited to women who experience only physical abuse or trauma, as even psychological IPV has been linked to poor pregnancy outcomes. Many maternal factors are associated with pregnancy IPV, including physical and mental health problems, and negative health behaviors. Causality has not been established, and thus the direction of these relationships is not known. However, knowledge of the maternal characteristics statistically associated with pregnancy IPV can provide useful information to clinicians attempting to identify women experiencing or risk for experiencing IPV. Again, while any woman could be a potential victim, those most likely to be experiencing pregnancy IPV are women with recurrent pregnancy infections, including STDs, women who suffer from depression or anxiety, women with inadequate prenatal care utilization, those who fail to gain adequate weight, and women who smoke, consume alcohol, or use illicit substances during pregnancy. Knowledge of these characteristics and related demographic factors described in the previous section, together with the use of validated IPV assessment tools described in the subsequent section, can aid health care providers in the identification of women most at risk for IPV.

\section{Screening and management}

Many professionals and organizations have addressed IPV by recommending universal screening and promoting zero tolerance for IPV. Nearly two decades ago, the American Medical Association recommended screening all women presenting to primary care and many secondary care specialties. ${ }^{156}$ Similar recommendations have been advanced by the American Academy of Family Physicians, ${ }^{157}$ the American College of Nurse-Midwives (ACNM), ${ }^{158}$ the Joint Commission on
Accreditation of Health Care Organizations, ${ }^{159}$ and the World Health Organization. ${ }^{160}$ The American College of Obstetricians and Gynecologists (ACOG) has recommended that women be screened for IPV routinely at preconception, family planning, and gynecologic visits, as well as at the first prenatal visit, at least once per trimester, and at post partum checkup. ${ }^{161}$ Reinforcing their commitment to addressing IPV, ACOG sent material to all 28,000 members about IPV, including signs of abuse. ${ }^{162}$ ACOG and ACNM have been particularly proactive, as pregnancy may be the only time a woman will regularly access health care. ${ }^{128,163,164}$ In addition to the position statements of the professional organizations, based on the findings of their own and other studies, many researchers and clinicians have also advocated for universal IPV screening in health care settings. ${ }^{44,127,145,165}$

\section{Screening attitudes and practices}

Despite the recommendations, screening for IPV in health care settings in general, and during pregnancy in particular, is far from universal. Studies vary widely in findings related to whether providers believe they should screen and whether they actually do screen female patients for IPV. For example, a US survey of primary care resident physicians revealed that $95 \%$ thought screening for IPV was 'important.' ${ }^{166}$ A survey of Scottish midwives found only $66 \%$ thought they should ask patients about IPV, ${ }^{167}$ while a study involving obstetricians in Pakistan found just under half felt women should be routinely screened for IPV. ${ }^{168}$ Additionally, a British study revealed that only $15 \%$ of general practitioners and practice nurses felt they should be routinely asking about IPV. ${ }^{169}$ In a survey of over 300 primary care physicians in the US, only $6.2 \%$ reported screening for IPV at initial visits, and only $7.5 \%$ did at annual exams. ${ }^{170}$ In other studies, anywhere from $10 \%-65 \%$ of US physicians report following ACOG screening guidelines for IPV during pregnancy. ${ }^{171-173}$ A study in Belgium revealed only $8 \%$ of gynecologists routinely screened for IPV, ${ }^{167}$ while in a Canadian study, $42 \%$ of physicians reported routinely screening for IPV. ${ }^{174}$ Unfortunately, surveys of patients themselves often result in even lower screening prevalence estimates. In two separate samples, only $6 \%{ }^{175}$ and $18 \%{ }^{176}$ of women recalled having been asked about IPV by their physician. This disconnect between what physicians say they do and what patients remember being asked was especially evident in a survey of physicians and their female patients, where $33 \%$ of physicians said they screen for IPV, while only $7 \%$ of their patients recall being asked about IPV. ${ }^{177}$ These and similar findings led the authors of a comprehensive review to conclude that the majority 
of health care providers do not find a universal screening program for IPV acceptable or practical, with acceptance rates ranging from $15 \%-95 \%$ across studies worldwide. ${ }^{178}$ They did note, however, that acceptability of IPV screening was generally higher in the US than in other countries examined. Finally, because of these widely varying prevalence rates of acceptance and practice related to IPV screening, the CDC concluded in 2004 that the extent to which US clinicians incorporate screening for IPV into their practices is relatively unknown. ${ }^{179} \mathrm{~A}$ comprehensive review on studies in dozens of countries reached a similar conclusion with respect to screening practice rates in other countries. ${ }^{178}$

Additional research has been conducted to investigate why, despite national policies and recommendations, health care providers are not screening all of their female patients, and pregnant women in particular, for IPV. Failure to screen is unfortunate, as a recent study revealed disclosure of IPV to increase from $5 \%$ to $30 \%$ after implementation of universal screening. ${ }^{180}$ Others have reported that when asked directly about IPV, most women will answer honestly if separated from their batterers. ${ }^{181}$ Multiple reasons for failure to screen have been advanced, including general provider unwillingness as described above. However, the most common barrier to IPV screening in health care settings appears to be time, ${ }^{182,183}$ with as many as $46 \%$ of providers citing time constraints as the primary reason for not screening all female patients for IPV. $^{184}$ Other reasons offered for failure to routinely screen for IPV include lack of confidence and personal discomfort, belief that women will not disclose abuse or seek help, and not knowing what to do if IPV is revealed. ${ }^{178}$ Additionally, most providers cite a lack of knowledge in IPV assessment. Indeed, in a recent US survey, $96 \%$ of physicians believed that training in domestic violence screening should be included in medical education, ${ }^{185}$ while a recent study in Belgium revealed that fewer than $7 \%$ of gynecologists had ever received any education or training in IPV assessment. ${ }^{186}$

Unfortunately, even when health care providers do inquire about IPV, some women still do not disclose their experiences. A Canadian study found that only $29 \%$ of women who experienced IPV have discussed it with their health care provider. ${ }^{187}$ Reasons for failure to disclose have been summarized in multiple papers and include fear of retaliation, being blamed, that others won't understand, lack of confidentiality, losing their children, losing what little control they have, economic or psychological dependence on the abuser, and the promise of change ${ }^{39,188}$ Despite this, certain circumstances increase the likelihood that women will disclose IPV to their health care providers including direct, repeated, and behaviorally specific questioning. ${ }^{7,20,21,173}$ As discussed previously, asking questions about specific behaviors, and avoiding terms such as "abuse" are key to accurate disclosure. For example, after being asked if they had been abused by their partner, $38 \%$ of women changed their answer from no to yes when follow-up questioning was behaviorally specific. ${ }^{116}$ In general, both abused and non-abused women don't mind being asked, and in fact agree and expect that providers should screen women for IPV. ${ }^{189-192}$ In one study, $96 \%$ of a sample of over 1,300 women asked prenatally felt ' $\mathrm{OK}$ ' about being asked, ${ }^{192}$ and in another study, it was actually the abused women who were 1.5 times more likely than those not abused to agree with universal screening. ${ }^{193}$ A recent comprehensive review on the topic concluded that most women found IPV screening in a health care setting acceptable, provided the health care professional was sensitive, nonjudgmental, and they did not feel the information revealed would be used to show they were not caring for their children properly. ${ }^{178}$ All of these findings have led researchers to conclude that if the impact of IPV is ever to be reduced, it is imperative that health care professionals routinely screen all women for IPV. ${ }^{4,143,163}$

\section{Screening tools}

Many health care provider attempts to screen for IPV involve asking only one question. Unfortunately, recent research has suggested that responses to single IPV items do not correspond to scores on longer, standardized measures ${ }^{194}$ In fact, in one study of prenatal patients, single item responses were completely unrelated to both verbal aggression $(r=0.03)$ and violence $(\mathrm{r}=-0.05)$ scales of the well validated Conflict Tactics Scale (CTS). ${ }^{195}$ The CTS, ${ }^{196}$ and the more recent modification the CTS2, ${ }^{197}$ have long been regarded as the gold standard of IPV assessment, ${ }^{198}$ and take $10-15$ minutes to complete. While the original CTS2 asks questions about IPV based on occurrences in the past year, the authors permit use of other referent periods, ${ }^{197}$ and pregnancy studies typically ask about occurrences in the 12 months before pregnancy, and separately for occurrences since the beginning of pregnancy. ${ }^{145}$ Other IPV tools of similar length include the Index of Spouse Abuse, ${ }^{199}$ the Severity of Violence Against Women Scale, ${ }^{200}$ and the Abuse Risk Inventory. ${ }^{201}$

Due to the length of the CTS2 and other tools listed above, and the fact noted that providers often fail to screen due to time constraints, these tools are not practical for use in clinical settings. Even short versions contain, at a minimum, 24 items. ${ }^{197}$ Thus, many shorter IPV measures more appropriate for clinical use have been developed in the last two decades. The CDC have recently developed a 
compendium of brief partner violence assessment tools that are recommended for use in health care settings. ${ }^{202}$ This publication includes dozens of tools, including information about their administration and psychometric properties, and is an excellent provider resource. Some of the more commonly used tools are described here. The five-item AAS, ${ }^{203}$ is a commonly used IPV screen due to ease of administration and established reliability and validity. ${ }^{35}$ The AAS is most sensitive to major physical violence, but is less accurate in identifying women who have experienced minor physical or emotional abuse. ${ }^{178}$ In addition to the AAS, several other measures that screen for IPV are available. The seven-item Woman Abuse Screening Tool (WAST) 204 was specifically designed for use in family practice settings to identify female patients experiencing emotional and/or physical abuse by their intimate partner (Appendix 1). While comprehensive for a screening tool, cut-points for determination of abuse have not been well validated. ${ }^{178} \mathrm{~A}$ similar measure, the four-item HITS, ${ }^{205}$ was designed by a focus group of family physicians for use in outpatient clinical settings (Appendix 2). HITS is an acronym, representing the four questions asking about "Hits," "Insults," "Threatens," and "Screams," making it easier for providers to remember. Questions are answered on a five-point scale, with a cut-off of 10.5 maximizing both sensitivity and specificity. ${ }^{178}$ In contrast to the AAS and HITS, which assess how much and to what degree IPV is occurring, the 15-item Danger Assessment scale (DA) ${ }^{116}$ measures risk of extreme consequences of IPV.

The US Preventive Service Task Force has concluded that there is still insufficient evidence to recommend one IPV screening tool over another. ${ }^{159}$ While further research is needed to determine the most appropriate and effective way to assess IPV in clinical settings, ${ }^{206}$ some comparative findings have been published. A recent study of women's preferences for IPV screening revealed the WAST to be preferable over other standardized tools. ${ }^{192}$ While acceptability of a tool to patients will likely increase disclosure, such data do not tell us about the reliability and validity of various screening tools. Feder and colleagues conducted a comprehensive review of dozens of studies from across the world, many of which involved comparisons of various screening tools to gold standards such as the CTS. ${ }^{178}$ They concluded that the HITS screening tool demonstrates the best predictive power, validity, and reliability, and is also the easiest for providers to remember. However, this tool does not ask about sexual abuse or ongoing violence, and thus may need to be combined with another screening tool. They review authors also concluded that the WAST and AAS perform almost as well as the HITS in health care settings. Thus, it appears that any of these three tools could be effectively used by prenatal care providers to screen for IPV in their patients.

\section{Management and intervention}

While we are beginning to learn about the best way to screen for IPV during pregnancy, much less is known about how to effectively manage this problem once it is identified. Indeed, as described above, many providers do not routinely screen for IPV because they do not know what they should do if it is discovered. This is unfortunate as studies have revealed that disclosure of abuse in a health care setting, even in the absence of a subsequent intervention, can reduce the incidence of additional violence. ${ }^{207}$ A recent survey of US physicians, with obstetricians the largest specialty group included, examined attitudes about managing IPV in patients. ${ }^{208}$ Most responders $(85 \%)$ felt the work was significant, although few $(11 \%)$ had overall positive feelings about it. Most felt helping IPV victims was stressful, difficult, and risky. Additionally, the majority of respondents reported no or minimal training in addressing IPV with patients, and the majority scored below $80 \%$ on an IPV knowledge test. The study authors concluded that health care workers need additional training and support in order to effectively manage patients experiencing IPV.

Several options are available to health care providers in the management of patients, and pregnant women in particular, who are being abused. The first type is interventions for the women themselves. Health care providers with training in this area may be able to provide limited counseling in the form of a brief intervention or motivational interviewing. However, lack of time and experience precludes this option in the vast majority of cases. Other more commonly employed options are referrals to safe environments, including family members or shelters, referrals to counseling or other community based resources, and the provision of resource information. Another set of intervention options is referral of the perpetrator to a batterer treatment program. The practicality of this approach is somewhat limited, however, if the provider has no contact with the abuser or the abuser is unwilling to seek help. However, along these lines, a woman who is being physically abused can be encouraged to file legal charges or seek a protective order.

Unfortunately, few published studies provide data to demonstrate the effectiveness of any of the above management options. One exception is a report on a US intervention project involving six telephone calls from a nurse over an eight-week period in which safety-promoting behaviors were 
discussed. ${ }^{209}$ Compared to controls, women who received the phone calls engaged in significantly more safety-promoting behaviors at follow-up. A handful of reports can be found on projects outside the US and Europe. One is an initial report on an IPV intervention implemented in Australia which focused on the provision of a community mentor to provide assistance, support, and advocacy. ${ }^{210}$ While preliminary data suggest this approach is somewhat effective, final data are not yet available. A second report is from a study in Nicaragua with an intervention focused simply on inquiring about possible IPV discussing attitudes toward it. ${ }^{47}$ While the majority of women reported that their abuse had ended at follow-up, no control group was used in this study, limiting the usefulness of the findings.

Two recent reviews have attempted to synthesize what we know about the effectiveness of treatment options in North America and Europe for women experiencing IPV. The first was conducted by Wathen and MacMillan, published in 2003. ${ }^{211}$ They reviewed management options for both the victim and the abuser. In terms of studies on interventions for women, most involved examining the effectiveness of shelter stays, advocacy counseling, personal and vocational counseling, and enhanced prenatal counseling addressing IPV. The highest quality rating of any of the studies was "fair," indicating that outcomes were based on self-report and/or tools used were of uncertain validity. While all studies reviewed had methodological weaknesses, some conclusions could be drawn. First, no current evidence of suitable quality exists to evaluate the effectiveness of a shelter stay to decrease the incidence of violence. While this does not mean that a shelter stay may not be useful for some abused women, further research is needed to more definitely evaluate the effectiveness of this option. However, there was fair evidence to suggest that a shelter stay combined with advocacy counseling can decrease the rate of re-abuse and improve quality of life over the next two years. ${ }^{211}$ Thus, it appears that health care providers may be able to effectively manage IPV in their female patients, and pregnant patients in particular, by becoming aware of both shelter and advocacy programs in their area, and encouraging patients they identify as experiencing IPV to use these services.

The Wathen and MacMillan review ${ }^{211}$ also examined studies that targeted male batterers, either alone or with their partners. These interventions have been more thoroughly studied, and thus evidence about their effectiveness is more readily available. Unfortunately, most programs that work with abusers to decrease the incidence of IPV have not been shown to be effective. In contrast, there is some evidence to suggest that arrest of the perpetrator, and the use of protective orders, can be effective in some cases. However, there is also data demonstrating that in some cases this approach can actually lead to an escalation of violence, especially when the perpetrator is unemployed or otherwise has little to lose by not complying with the legal system. Finally, initial data suggest that protection orders combined with legal advocacy and counseling may reduce the incidence of re-perpetration for many men. Thus, health care providers can also help to manage IPV in patients by having information available about the legal system and local options for assistance for batterers.

A more recent Cochrane review, conducted by Ramsay and colleagues, ${ }^{212}$ specifically examined the effectiveness of IPV interventions for women that involved advocacy. Ten studies were found that met inclusion criteria, and all differed in type and intensity of advocacy, outcomes assessed, and duration of follow-up. Overall, they found that intensive advocacy (12 hours or more total) as part of or after a shelter stay improved quality of life at up to 12 months follow-up, and increased the chances of termination of physical abuse at up to 24 months follow up. Intensive advocacy was not found to impact either depression or psychological distress. Minimal data were available to definitively evaluate the effectiveness of brief advocacy interventions, but evidence suggests they do increase the use of safety behaviors both short and long term, even for women who remain with the perpetrator. However, the authors conclude that while intensive advocacy is likely to be most effective, further research is needed to determine the utility of briefer advocacy interventions, both for women who leave or who remain with the perpetrating partner. ${ }^{212}$

\section{Conclusion}

It is clear that pregnancy IPV is a significant problem worldwide and is associated with adverse newborn outcomes. Many mechanisms for how IPV may impact LBW and preterm births have been proposed and include direct health, mental health, and behavioral effects, all of which may help providers identify women most at risk. Screening for IPV during pregnancy is essential, yet due to time constraints and few clear recommendations for assessment, many prenatal providers do not routinely inquire about IPV. More training is needed to assist health care providers in identifying and managing pregnancy IPV, with additional research needed to inform effective interventions to reduce the rates of pregnancy IPV and resultant outcomes. 


\section{Disclosure}

The author reports no conflicts of interest in this work.

\section{References}

1. Campbell JC, Humphries J. Nursing Care of Survivors of Family Violence. St Louis, MO: Mosby-Yearbook; 1993.

2. Shadigian EM, Bauer ST. Screening for partner violence during pregnancy. Int J Gynaecol Obstet. 2004;84:273-280.

3. National Research Council. Understanding Violence Against Women. Washington, DC: National Academy Press; 1996.

4. Walton-Moss BJ, Campbell J. Intimate partner violence: implications for nursing. Online J Issues Nurs. 2002;7(1):5.

5. Petersen R, Saltzman LE, Goodwin MM, Spitz A. Key Scientific Issues for Research on Violence Occurring Around the Time of Pregnancy. Report to the CDC. Atlanta, GA: CDC; 1998.

6. American Medical Association. Diagnostic and treatment guidelines on domestic violence. Arch Fam Med. 1992;1:39-47.

7. Gazmararian JA, Lazorick S, Spitz AM, Ballard T, Saltzman L, Marks JS. Prevalence of violence against pregnant women. JAMA. 1996;275:1915-1920.

8. D'Avolio D, Hawkins JW, Haggerty LA, et al. Screening for abuse: Barriers and opportunities. Health Care Women Int. 2001;22: 349-362.

9. Harrykissoon SD, Rickert VI, Wiemann CM. Prevalence and patterns of intimate partner violence among adolescent mothers during the postpartum period. Arch Pediatr Adolesc Med. 2002;156: 325-330.

10. Mitchell C. The health impact of intimate partner violence. J Calif Dent Assoc. 2004;32:396-398.

11. Centers for Disease Control and Prevention, National Center for Injury Prevention and Control. Costs of Intimate Partner Violence Against Women in the United States. Atlanta, GA: CDC; 2003.

12. Rennison CM. Intimate Partner Violence, 1993-2001: Crime Data Brief. Washington, DC: Bureau of Justice Statistics, US Department of Justice; 2003.

13. US Surgeon General. Report: Surgeon General's Workshop on Violence and Public Health. Washington, DC: US Department of Health and Human Services, Public Health Service; 1986.

14. US Department of Health and Human Services. Healthy People 2010. Washington, DC: US Government Printing Office; 2001.

15. Bachman R, Saltzman LE. Violence Against Women: Estimates from the Redesigned Survey. Washington, DC: Bureau of Justice Statistics, US Department of Justice; 1995.

16. Campbell JC, Soeken KL. Forced sex and intimate partner violence: effects on women's risk and women's health. J Interpers Violence. 1999;5:1017-1035.

17. Tjaden P, Thoennes N. Prevalence, Incidence, and Consequences of Violence Against Women: Findings from the National Violence Against Women Survey. Washington, DC: National Institute of Justice, Centers for Disease Control and Prevention; 1998.

18. Campbell JC, Lewandowski LA. Mental and physical health effects of intimate partner violence on women and children. Psychiatr Clin North Am. 1997;20:353-374.

19. Neggers Y, Goldenberg R, Cliver S, Hauth J. Effects of domestic violence on preterm birth and low birth weight. Acta Obstet Gynecol Scand. 2004;83:455-460.

20. Norton L, Peipert J, Zierler S, Lima B, Hume L. Battering in pregnancy: an assessment of two screening methods. Obstet Gynecol. 1995;85:321-325.

21. Stenson K, Heimer G, Lundh C, Nordstrom ML, Saarinen H, Wenker A. The prevalence of violence investigated in a pregnant population in Sweden. J Psychosom Obstet Gynaecol. 2001;22: 189-197.
22. Shumway J, O'Campo P, Gielen A, Witter FR, Khouzami AN, Blakemore KJ. Preterm labor, placental abruption, and premature rupture of membranes in relation to maternal violence or verbal abuse. J Matern Fetal Med. 1999;8:76-80.

23. D'Avolio D, Hawkins JW, Haggerty LA, et al. Screening for abuse: Barriers and opportunities. Health Care Women Int. 2001;22:349-362.

24. Australian Bureau of Statistics. Personal Safety, Australia 2005. Canberra, Australia: Australian Bureau of Statistics; 2006.

25. Ahmad F, Hogg-Johnson S, Stewart DE, Levinson W. Violence involving intimate partners: prevalence in Canadian family practice. Can Fam Physician. 2007;53(3):461-468.

26. Ruiz-Perez I, Plazaola-Castano J, Del Rio-Lozano M. Physical health consequences of intimate partner violence in Spanish women. Eur $J$ Public Health. 2007;17(5):437-443.

27. O'Leary KD, Tintle N, Bromet EJ, Gluzman SF. Descriptive epidemiology of intimate partner aggression in Ukraine. Soc Psychiatry Psychiatr Epidemiol. 2008;43(8):619-626.

28. Ntaganira J, Muula AS, Masaisa F, Dusabeyezu F, Siziya S, Rudatsikira E. Intimate partner violence among pregnant women in Rwanda. BMC Women Health. 2008;8:17.

29. Ellsberg MC, Pena R, Herrera A, Liljestrand J, Winkvist A. Wife abuse among women of childbearing age in Nicaragua. Am J Public Health. 1999;89(2):241-244.

30. Perales MT, Cripe SM, Lam N, Sanchez E, Williams MA. Prevalence, types, and pattern of intimate partner violence among pregnancy women in Lima, Peru. Violence Against Women. 2009;15(2):224-250.

31. Silverman JG, Decker MR, Saggert N, Balaiah D, Raj A. Intimate partner violence and HIV infection among married Indian women. JAMA. 2008;300(6):703-710.

32. Garcia-Moreno C, Jansen HA, Ellsberg M, Heise L, Watts CH. Prevalence of intimate partner violence: findings from the WHO multi-country study on women's health and domestic violence. Lancet. 2006;368(9542):1260-1269.

33. Heise L, Ellsberg M, Gottemoeller M. Ending Violence Against Women (Population Report, Series L, no 11). Baltimore, MD: Johnson Hopkins University School of Public Health, Center for Communications Programs; 1999.

34. United Nations. Fourth World Conference on Women. September, 1995. Available from: http://www.un.org/womenwatch/daw/beijing/ index.html. Accessed July 1, 2008.

35. Jasinski JL. Pregnancy and domestic violence. Trauma Violence Abuse. 2004;5(1):47-64.

36. Humphreys J, Parker B, Campbell J. Intimate partner violence against women. In: Fitzpatrick JJ, Taylor D, Fugate-Woods N, editors. Annual Review of Nursing Research Volume 19. New York, NY: Springer; 2001:275-306.

37. Centers for Disease Control and Prevention. PRAMS 1996 Surveillance Report. Atlanta, GA: Division of Reproductive Health, National Center for Chronic Disease Prevention and Health Promotion, Centers for Disease Control and Prevention; 1997.

38. Fanslow J, Silva M, Robinson E, Whitehead A. Violence during pregnancy: associations among a representative sample of New Zealand women. Aust N Z J Obstet Gynaecol. 2008;48(4):398-404.

39. Griffin MP, Koss MP. Clinical screening and intervention in cases of partner violence. Online J Issues Nurs. 2002;7(1):3.

40. Sagrestano LM, Rodriguez AC, Carroll D, et al. A comparison of standardized measures of psychosocial variables with single-item screening measures used in an urban obstetric clinic. J Obstet Gynecol Neonatal Nurs. 2002;31(2):147-155.

41. Jasinski JL, Kantor GK. Pregnancy, stress and, wife assault: ethnic differences in prevalence, severity, and onset in a national sample. Violence Vict. 2003;16(3):219-232.

42. Curry MA. The interrelationships between abuse, substance use, and psychosocial stress during pregnancy. J Obstet Gynecol Neonat Nurs. 1998;27:692-699. 
43. Norton LB, Peipert JF, Zierler S, Lima B, Hume L. Battering in pregnancy: an assessment of two screening methods. Obstet Gynecol. 1995;85:321-325.

44. Dunn LL, Oths KS. Prenatal predictors of intimate partner abuse. J Obstet Gynecol Neonatal Nurs. 2004;33:54-63.

45. McFarlane J, Parker B, Soeken K. Abuse during pregnancy: associations with maternal health and infant birth weight. Nurs Res. 1996;45:37-42.

46. Coker AL, Sanderson M, Dong B. Partner violence during pregnancy and risk of adverse pregnancy outcomes. Paediatr Perinat Epidemiol. 2004;18:260-269.

47. Salazar M, Valladares E, Ohman A, Hogberg U. Ending intimate partner violence after pregnancy: findings from a community-based longitudinal study in Nicaragua. BMC Public Health. 2009;9:350.

48. Deveci SE, Acik Y, Gulbayrak C, Tokdemir M, Ayar A. Prevalence of domestic violence during pregnancy in a Turkish community. Southeast Asian J Trop Med Public Health. 2007;38(4):754-760.

49. Fikree FF, Jafarey SN, Korejo R, Afshan A, Durocher JM. Intimate partner violence before and during pregnancy: experiences of postpartum women in Karachi, Pakistan. J Pak Med Assoc. 2006;56(6):252-257.

50. Varma D, Chandra PS, Thomas T, Carey MP. Intimate partner violence and sexual coercion among pregnant women in India: relationship with depression and post-traumatic stress disorder. $J$ Affect Disord. 2007;102:227-235.

51. Roelens K, Verstraelen H, VanEgmond K, Temmerman M. Disclosure and health seeking behavior following intimate partner violence before and during pregnancy in Flanders, Belgium: a survey surveillance study. Eur J Obstet Gynecol Reprod Biol. 2008;137:37-42.

52. Shumway J, O'Campo P, Gielen A, Witter FR, Khouzami AN, Blakemore KJ. Preterm labor, placental abruption, and premature rupture of membranes in relation to maternal violence or verbal abuse. J Mater Fetal Med. 1999;8:76-80.

53. Bailey BA, Daugherty RA. Intimate partner violence during pregnancy: incidence and associated health behaviors in a rural population. Matern Child Health J. 2007;11:495-503.

54. Bullock LFC, Mears JLC, Woodcock C, Record R. Retrospective study of the association of stress and smoking during pregnancy in rural women. Addict Behav. 2001;26:405-413.

55. Ventura SJ, Martin JA, Curtin SC, Mathews TJ. Advance report of final natality statistics, 1995. Mon Vital Stat Rep. 1997;45 Suppl 11:S1-S84.

56. Rennison C, Welchans S. Bureau of Justice Statistics Special Report: $I P V$. Washington, DC: US Department of Justice, Office of Justice Programs; 2000.

57. Dunn LL, Oths KS. Prenatal predictors of intimate partner abuse. J Obstet Gynecol Neonatal Nurs. 2004;33:54-63.

58. Coker AL, Sanderson M, Dong B. Partner violence during pregnancy and risk of adverse pregnancy outcomes. Paediatr Perinatal Epidemiol. 2004;18:260-269.

59. Centers for Disease Control and Prevention. Physical violence and injuries in intimate relationships - New York, Behavioral Risk Factor Surveillance System, 1994. Morb Mortal Wkly Rep. 1996;45:765-767.

60. Centers for Disease Control and Prevention: Lifetime and annual incidence of intimate partner violence and resulting injuries - Georgia, 1995. Morb Mortal Wkly Rep. 1998;47:849-853.

61. Saltzman LE, Johnson CH, Gilbert BC, Goodwin MM. Physical abuse around the time of pregnancy: an examination of prevalence and risk factors in 16 states. Matern Child Health J. 2003;7(1):31-43.

62. Bohn DK, Tebben JG, Campbell JC. Influences of income, education, age, and ethnicity on physical abuse before and during pregnancy. J Obstet Gynecol Neonatal Nurs. 2004;33(5):561-571.

63. Jeyaseelan L, Sadowski LS, Kumar S, Hassan F, Ramiro L, Vizzcarra B. World studies of abuse in the family environment - risk factors for physical intimate partner violence. Inj Control Saf Promot. 2004;11(2):117-124.
64. Gelles RJ. Violence and pregnancy: are pregnant women at greater risk of abuse? In: Straus MA, Gelles RJ, editors. Physical Violence in American Families: Risk Factors and Adaptations to Violence in 8,145 Families. New Brunswick, NJ: Transaction Books; 1990: 279-286.

65. Parker B, McFarlane J, Soeken K, Torres S, Campbell D. Physical and emotional abuse in pregnancy: a comparison of adult and teenage women. Nurs Res. 1993;42:173-178.

66. Anderson BA, Marshak HH, Hebbeler DL. Identifying intimate partner violence at entry to prenatal care: clustering routine clinical information. J Midwifery Womens Health. 2002;47(5):353-359.

67. Saltzman LE, Johnson CH, Gilbert BC, Goodwin MM. Physical abuse around the time of pregnancy: an examination of prevalence and risk factors in 16 states. Matern Child Health J. 2003;7(1): 31-43.

68. Halinka Malcoe L, Duran BM, Montgomery JM. Socioeconomic disparities in intimate partner violence against Native American women: a cross-sectional study. BMC Med. 2004;2:20.

69. Field CA, Caerano R. Ethnic differences in intimate partner violence in the US general population: the role of alcohol use and socioeconomic status. Trauma Violence Abuse. 2004;5(4):303-317.

70. Mattison D, Damus K, Fiore E, Petrini J, Alter C. Preterm delivery: a public health perspective. Paediatr Perinatal Epidemiol. 2001;15 Suppl 2: S7-S16.

71. Hack M, Klein NK, Taylor G. Long-term developmental outcomes of low birth weight infants. Future Child. 1995;5:176-196.

72. Kilbride HW, Thorstad K, Daily DK. Preschool outcome of less than 801 gram preterm infants compared with full-term siblings. Pediatrics. 2004;113(4):742-747.

73. Marlow N. Neurocognitive outcome after very preterm birth. Arch Dis Child Fetal Neonatal Ed. 2004;89:224-228.

74. Taylor HG, Minich NM, Klein N, Hack M. Longitudinal outcomes of very low birth weight: neuropsychological findings. J Int Neuropsychol Soc. 2004;10:149-163.

75. Goldenberg RL, Hoffman HJ, Cliver SP. Neurodevelopmental outcome of small-for-gestational-age infants. Eur J Clin Nutr. 1998;52 Suppl 1: S54-S58.

76. Roth S, Wyatt J, Baudin J, et al. Neurodevelopmental status at 1 year predicts neuro-psychiatric outcome at 14-15 years of age in preterm infants. Early Human Develop. 2001;65:81-89.

77. Villar J, Smeriglio V, Martorell R, Brown CH, Klein RE. Heterogeneous growth and mental development of intrauterine growth-retarded infants during the first 3 years of life. Pediatrics. 1984;74(5): 783-791.

78. Goldenberg RL, Hack M, Grantham-McGregor SM, Schurch B. Report of the IDECG/IUNS Working Group on IUGR effects on neurological, sensory, cognitive, and behavioral function. Eur J Clin Nutr. 1998;52 Suppl 1:S100-S101.

79. Pryor J, Silva PA, Brooke M. Growth, development, and behavior in adolescents born small-for-gestational-age. J Paediatr Health. 1995;31(5):403-407.

80. Luciana M, Lindeke L, Georgieff MK, Mills MM, Nelson CA. Neurobehavioral evidence for working memory deficits in school-aged children with histories of prematurity. Develop Med Child Neurol. 1999;41:521-533.

81. Strauss RS. Adult functional outcome of those born small for gestational age: twenty-six-year follow-up of the 1970 British Birth Cohort. JAMA. 2000;283(5):625-632.

82. O'Keefe MJ, O'Callaghan M, Williams GM, Najman JM, Bor W. Learning, cognitive, and attentional problems in adolescents born small for gestational age. Pediatrics. 2003;112(2):301-307.

83. Westwood M, Kramer MS, Munz D, Lovett JM, Watters GV. Growth and development of full-term nonasphyxiated small-forgestational-age newborns: follow-up through adolescence. Pediatrics. 1983;71(3):376-382. 
84. Zubrick SR, Kurinczuk JJ, McDermott BM, McKelvey RS, Silburn SR, Davies LC. Fetal growth and subsequent mental health problems in children aged 4 to 13 years. Dev Med Child Neurol. 2000;42(1):14-20.

85. Piecuch RE, Leonard CH, Clyman RI, Cooper BA. Risk factors associated with infant death among very low birth weight infants after discharge from an intensive care nursery. J Dev Behav Pediatr. 1998;19(2):84-88.

86. Yount JE, Flanagan WJ, Dingley EF, Lewman LV. Evidence for an exponentially increasing incidence of sudden infant death syndrome (SIDS) with decreasing birthweight (BW). Pediatr Res. 1979;13:510.

87. Welliver RC. Review of epidemiology and clinical risk factors for severe respiratory syncytial virus (RSV) infection. J Pediatr. 2003;143 Supp1 5:S112-S117.

88. Boyce TG, Mellen BG, Mitchel EF Jr, Wright PF, Griffin MR. Rates of hospitalization for respiratory syncytial virus infection among children in Medicaid. J Pediatr. 2000;137:865-870.

89. Murphy CC, Schei B, Myhr T, DuMont J. Abuse: A risk factor for low birth weight? A systematic review and meta-analysis. Can Med Assoc J. 2001;164(11):1567-1572.

90. Dye T, Tolliver N, Lee R, Kenney C. Violence, pregnancy, and birth outcome in Appalachia. Paediatr Perinat Epidemiol. 1995;9:35-47.

91. Bohn DK. Lifetime and current abuse, pregnancy risks, and outcomes among Native American women. $J$ Health Care Poor Underserved. 2002;13(2):184-198.

92. Fernandez FM, Krueger PM. Domestic violence: effect on pregnancy outcome. J Am Osteopath Assoc. 1999;5:254-256.

93. Wang CS, Chou P. Differing risk factors for premature birth in adolescent mothers and adult mothers. J Chin Med Assoc. 2003;66:511-517.

94. Schoeman J, Grove D, Odendaal HJ. Are domestic violence and the excessive use of alcohol risk factors in preterm birth? J Trop Pediatr. 2005;51:49-50.

95. Rachana C, Suraiya K, Hisham AS, Abdulaziz AM, Hai A. Prevalence and complications of physical violence during pregnancy. Eur J Obstet Gynecol Reprod Biol. 2002;103:26-29.

96. Curry MA, Harvey SM. Stress related to domestic violence during pregnancy and infant birth weight. In: Campbell JC, editor. Empowering Survivors of Abuse. Thousand Oaks, CA: Sage; 1998.

97. Parker B, McFarlane J, Soeken K. Abuse during pregnancy: effects on maternal complications and birth weight in adult and teenage women. Obstet Gynecol. 1994;84:323-328.

98. Lipsky S, Holt VL, Easterling TR, Critchlow CW. Impact of policereported intimate partner violence during pregnancy on birth outcomes. Obstet Gynecol. 2003;102:557-564.

99. Shah AJ, Kilcline BA. Trauma in pregnancy. Emerg Med Clin North Am. 2003;21:615-629.

100. Pearlman MD, Tintinalli JE, Lorenz RP. Blunt trauma during pregnancy. N Engl J Med. 1990;323:1609-1613.

101. Ribe JK, Teggartz JR, Harvey CM. Blows to the maternal abdomen causing fetal demise: report of three cases and review of the literature. J Forensic Sci. 1993;38:1092-1096.

102. Sammons MN. Battered and pregnant. Am J Matern Child Nurs. 1982;6:246-250.

103. Bacchus L, Mezey G, Bewley S, Haworth A. Prevalence of domestic violence when midwives routinely enquire in pregnancy. BJOG. 2004;111:441-445.

104. Cokkinides VE, Coker AL, Sanderson M, Addy C, Bethea L. Physical violence during pregnancy: maternal complications and birth outcomes. Obstet Gynecol. 1999;93:661-666.

105. Muelleman RL, Lenaghan PA, Pakieser RA. Nonbattering presentations to the $\mathrm{ED}$ of women in physically abusive relationships. Am J Emerg Med. 1998;16:128-131.

106. Newberger E, Barkan S, Lieberman E, et al. Abuse of pregnant women and adverse birth outcomes: current knowledge and implications for practice. JAMA. 1992;267:2370-2373.
107. Curry MA, Perrin N, Wall E. Effects of abuse on maternal complications and birth weight in adult and adolescent women. Obstet Gynecol. 1998;92:530-534.

108. Sandhaus S. Genital herpes in pregnant and nonpregnant women. Nurse Pract. 2001;26:15-35.

109. Hillier SL, Nugent RP, Eschenbach DA, et al. Association between bacterial vaginosis and preterm delivery of a low birth weight infant. N Engl J Med. 1995;333:1737-1742.

110. Investigators of the Johns Hopkins Study of Cervicitis and Adverse Pregnancy Outcome. Association of chlamydia trachomatis and mycoplasma hominis with intrauterine growth retardation and preterm delivery. Am J Epidemiol. 1989;129:1247-1257.

111. Bacchus L, Mezey G, Bewley S. Domestic violence: prevalence in pregnant women and associations with physical and psychological health. Eur J Obstet Gynecol Reprod Biol. 2003;113:6-11.

112. National Research Council. Causes and consequences of violence against women. In: Crowell N, Burgess A, editors. Understanding Violence Against Women. Washington, DC: National Academy Press; 1996.

113. Smith MV, Rosenheck RA, Cavaleri MA, Howell HB, Poschman $\mathrm{K}$, Yonkers KA. Screening for and detection of depression, panic disorder, and PTSD in public obstetric clinics. Psychiatr Serv. 2004;55(4):407-414.

114. Hilberman E, Munson K. Sixty battered women. Victimology. 1977-1978;2:460-470.

115. Marcus SM, Flynn HA, Blow FC, Barry KL. Depressive symptoms among pregnant women screened in obstetric settings. $J$ Womens Health. 2003;12(4):373-380.

116. Campbell JC. Domestic homicide: risk assessment and professional duty to warn. MD Med J. 1994;3:885-889.

117. Gelles R, Straus MA. Intimate Violence. New York, NY: Simon and Schuster; 1988.

118. Houskamp BM, Foy D. The assessment of posttraumatic stress disorder in battered women. J Interpers Violence. 1991;6:367-375.

119. Orr S, Miller CA. Maternal depressive symptoms and the risk of poor pregnancy outcome. Epidemiol Rev. 1995;17:165-171.

120. Peacock JL, Anderson R. Preterm delivery: effects of socioeconomic factors, psychological stress, smoking, alcohol, and caffeine. $B M J$. 1995;311:531-535.

121. Berkowitz GS. An epidemiologic study of preterm delivery. Am J Epidemiol. 1981;113:81-92.

122. Cooper RL, Goldenberg R, Das A, et al. The preterm prediction study: maternal stress is associated with spontaneous preterm birth at less than 35 weeks gestation. Am J Obstet Gynecol. 1996;175:1286-1292.

123. Hedegard M, Henriksen TB, Sabroe S, Secher NJ. Psychological distress in pregnancy and preterm delivery. BMJ. 1993;307: 234-239.

124. Newton RW, Webster PAC, Binu PS, Maskrey N, Phillips AB. Psychosocial stress in pregnancy and its relation to the onset of premature labor. BMJ. 1979;2:411-413.

125. Altarac M, Strobino DM. Abuse during pregnancy and stress because of abuse during pregnancy and birthweight. J Am Med Womens Assoc. 2002;57(4):208-214.

126. Gennaro S, Hennessey MD. Psychological and physiological stress: Impact on preterm birth. J Obstet Gynecol Neonatal Nurs. 2003;32(5):668-675.

127. Boy A, Salihu HM. Intimate partner violence and birth outcomes: a systematic review. Int J Fertil Womens Med. 2004;49:159-164.

128. Winn N, Records K, Rice M. The relationship between abuse, sexually transmitted diseases, and group B streptococcus in childbearing women. Am J Matern Child Nurs. 2003;28(2):106-110.

129. Goodwin M, Gazmararian JA, Johnson CH, Gilbert BC, Saltzman LE, Group PW. Pregnancy intendedness and physical abuse around the time of pregnancy: findings from the Pregnancy Risk Assessment Monitoring System, 1996-1997. Matern Child Health J. 2000;4:85-92.

130. Taggert L, Mattson S. Delay in prenatal care as a result of battering in pregnancy: cross-cultural implications. Health Care Women Int. 1996;17:25-34. 
131. Herbst MA, Mercer BM, Beazley D, Meyer N, Carr T. Relationship of prenatal care and perinatal morbidity in low-birth-weight infants. Am J Obstet Gynecol. 2003;189:930-933.

132. Barnet B, Kuggan AK, Devoe M. Reduced low birth weight for teenagers receiving prenatal care at a school-based health center: effect of access and comprehensive care. J Adolesc Health. 2003;33: 349-358.

133. Chang SC, O’Brien KO, Nathanson MS, Mancini J, Witter FR. Characteristics and risk factors for adverse birth outcomes in pregnant black adolescents. J Pediatr. 2003;143:250-257.

134. Leslie JC, Galvin SL, Diehl SJ, Bennett TA, Buescher PA. Infant mortality, low birth weight, and prematurity among Hispanic, white and African American women in North Carolina. Am J Obstet Gynecol. 2003;188(5):1238-1240.

135. Loto OM, Ezechi OC, Kalu BKE, Loto AB. Poor obstetric performance of teenagers; is it age or quality of care related? J Obstet Gynecol. 2004;24(4):395-398.

136. Vintzileos AM, Ananth CV, Smulian JC, Scorza WE, Knuppel RA. The impact of prenatal care on postneonatal deaths in the presence and absence of antenatal high-risk conditions. Am J Obstet Gynecol. 2002;187(5):1258-1262.

137. Korenbrot CC, Simpson L, Phibbs CS. Prenatal care needs assessment comparing service use and outcomes in Fresno, CA. Public Health Rep. 1994;109(1):68-76.

138. Kearney MH, Haggerty LA, Munro BH, Hawkins JW. Birth outcomes and maternal morbidity in abused pregnant women with public versus private health insurance. J Nurs Scholarsh . 2003;35(4):345-349.

139. Johnson PJ, Hellerstedt WL, Pirie PL. Abuse history and nonoptimal prenatal weight gain. Public Health Rep. 2002;117:148-156.

140. Lagiou P, Tamimi RM, Mucci LA, et al. Diet during pregnancy in relation to maternal weight gain and birth size. Eur J Clin Nutr. 2004;58:231-237.

141. Abrams B, Selvin S. Maternal weight gain pattern and birth weight Obstet Gynecol. 1995;86:163-169.

142. Shapiro C, Sutija VG, Bush J. Effect of maternal weight gain on infant birth weight. J Perinat Med. 2000;28:428-431.

143. Kearney MH, Munro BH, Kelly U, Hawkins JW. Health behaviors as mediators for the effect of partner abuse on infant birth weight. Nurs Res. 2004;53(1):36-45.

144. Campbell JC, Torres S, Ryan J, et al. Physical and nonphysical partner abuse and other risk fators for low birth weight among full term and preterm babies: a multiethnic case-control study. Am J Epidemiol. 1999;150:714-726.

145. Martin SL, Beaumont JL, Kupper LL. Substance use before and during pregnancy: links to intimate partner violence. Am J Drug Alcohol Abuse. 2003;29(3):599-617.

146. Nordstrom-Klee B, Delaney-Black V, Covington C, Ager J, Sokol RJ. Growth from birth on of children prenatally exposed to drugs: a literature review. Neurotoxicol Teratol. 2002;24(4):481-488.

147. Chiriboga CA. Fetal alcohol and drug effects. Neurologist. 2003;9(6):267-279

148. Covington C, Nordstrom-Klee B, Ager J, Sokol RJ, Delaney-Black $\mathrm{V}$. Birth to age 7 growth of children prenatally exposed to drugs: a prospective cohort study. Neurotoxicol Teratol. 2002;24(4): 489-496.

149. Fried PA, Watkinson B, Gray R. Growth from birth to early adolescence in offspring prenatally exposed to cigarettes and marijuana. Neurotoxicol Teratol. 1999;21(5):513-525.

150. Secker-Walker RH, Vacek PM. Relationships between cigarette smoking during pregnancy, gestational age, maternal weight gain, and infant birthweight. Addict Behav. 2003;28:55-66.

151. Bailey BA, Jones Cole LK. Rurality and birth outcomes: findings from Southern Appalachia and the potential role of pregnancy smoking. J Rural Health. 2009;25(2):141-149.

152. Hotaling GT, Sugarman DB. An analysis of risk markers in husband to wife violence: the current state of knowledge. Violence Vict. 1986;1:101-124.
153. Hurd YL, Wang X, Anderson V, Beck O, Minko H, Dow-Edwards D. Marijuana impairs growth in mid-gestation fetuses. Neurotoxicol Teratol. 2005;27(2):221-229.

154. Cornelius MD, Taylor PM, Geva D, Day NL. Prenatal tobacco and marijuana use among adolescents: effects of offspring gestational age, growth, and morphology. Pediatrics. 1995;738-743.

155. Sokol RJ, Janisse JJ, Louis JM, et al. Extreme prematurity: an alcoholrelated birth effect. Alcohol Clin Exp Res. 2007;31(6):1031-1037.

156. American Medical Association. Diagnostic and treatment guidelines on domestic violence. Arch Fam Med. 1992;1:39-47.

157. American Academy of Family Physicians Commission on Special Issues and Clinical Interests. Family violence: an AAFP white paper. Am Fam Physician. 1994;50:1636-1646.

158. American College of Nurse-Midwives. Position Statement: Violence Against Women. Washington, DC: American College of Nurse-Midwives, 1997.

159. US Preventive Task Force. Guide to Clinical Preventive Services. 2nd ed. Baltimore, MD: Lippincott; 1996.

160. World Health Organization. Violence Against Women: A Priority Health Issue. Geneva, Switzerland: World Health Organization; 1997.

161. American College of Obstetricians and Gynecologists. Violence Against Women: Screening Tools - Domestic Violence. 2002. Available from: http://www.acog.org/departments/dept_notice. $\mathrm{cfm} ? \mathrm{recno}=17 \&$ bulletin $=585$. Accessed 2010 March 29.

162. American College of Obstetricians and Gynecologists. The Battered Woman (ACOG Technical Bulletin No. 124). Washington, DC: ACOG; 1989.

163. McFarlane J, Soeken K, Wiist WH. An evaluation of interventions to decrease intimate partner violence in pregnant women. Public Health Nurs. 2000;17(6):443-451.

164. Campbell JC. Abuse during pregnancy: progress, policy, and potential. Am J Public Health. 1998;88:185-187.

165. Seng JS. A conceptual framework for research on lifetime violence, posttraumatic stress, and childbearing. J Midwifery Womens Health. 2002;47(5):337-346.

166. Baig A, Shadigian E, Heisler M. Hidden from plain sight: Residents' domestic violence screening attitudes and reported practices. J Gen Intern Med. 2006;21:949-954.

167. Barnett C. Exploring midwives' attitudes to domestic violence screening. Br J Midwifery. 2005;13:702-705.

168. Fikree FF, Jafarey SN, Korejo R, Khan A, Durocher JM. Pakistani obstetricians' recognition of and attitude towards domestic violence screening. Int J Gynecol Obstet. 2004;87(1):59-65.

169. Richardson J, Feder G, Eldridge S, Chung WS, Coid J, Moorey S. Women who experience domestic violence and women survivors of childhood sexual abuse: a survey of health professionals' attitudes and clinical practice. Br J Gen Pract. 2001;51:468-470.

170. Chamberlain L, Perham-Hester KA. The impact of perceived barriers on primary care physicians' screening practices for female partner abuse. Women Health. 2002;35:55-69.

171. Perrin KM, Boyett TP, McDermott RJ. Continuing education about physically abusive relationships: does education change the perceptions of health care practitioners? J Contin Educ Nurs. 2000;31(6):269-274.

172. Parsons LH, Zaccaro D, Well B, Stovall TG. Methods of and attitudes toward screening obstetrics and gynecology patients for domestic violence. Am J Obstet Gynecol. 1995;173:381-386.

173. Rodriguez M. Screening and intervention for intimate partner abuse: practices and attitudes of primary care physicians. JAMA 1999;282:468-474.

174. Gutmanis I, Beyon C, Tutty L, Wathen CN, MacMillan HL. Factors influencing identification of and response to intimate partner violence: a survey of physicians and nurses. BMC Public Health. 2007; $7: 12$.

175. Hamberger LK, Saunders DG, Hovey M. Prevalence of domestic violence in community practice and rate of physician inquiry. Fam Med. 1992;24:283-287. 
176. McGrath ME, Hogan JW, Peipert JF. A prevalence survey of abuse and screening for abuse in urgent care patients. Obstet Gynecol. 1998;91:511-514.

177. Friedman LS, Samet JH, Roberts MS, Hudlin M, Hans P. Inquiry about victimization experiences: a survey of patient preferences and physician practices. Arch Intern Med. 1992;152:1186-1190.

178. Feder G, Ramsay J, Dunne D. How far does screening women for domestic (partner) violence in different health-care settings meet criteria for a screening programme? Systematic reviews of nine UK National Screening Committee criteria. Health Technol Assess. 2009; $13: 16$.

179. Centers for Disease Control and Prevention. Addressing Violence Against Women: Results from a National Survey of Title X Family Planning Providers. Atlanta, GA: Centers for Disease Control and Prevention; 2004.

180. Freud KM, Bak SM, Blackall L. Identifying domestic violence in primary practice. J Intern Med. 1996;11:44-46.

181. Saltzman LE. Battering during pregnancy: a role for physicians. Altanta Med. 1990;64(3):45-48.

182. Wiebe ER, Janssen PA. Universal screening for domestic violence in abortion. Womens Health Issues. 2001;11(5):436-441.

183. Mezey G, Bacchus L, Haworth A, Bewley S. Midwives perceptions and experiences of routine enquiry for domestic violence. BJOG. 2003;110:744-752.

184. D'Avolio D, Mahoney MA. Integrated Community Response: Domestic Violence Action Plan. Unpublished manuscript. Boston, MA; Northeastern University; 1998.

185. Reid MA, Glasser M. Primary care physician's recognition of and attitudes toward domestic violence. Acad Med. 1997;5:153-158.

186. Roelens K, Verstraelen H, VanEgmond K, Temmerman M. A knowledge, attitudes, and practice survey among obstetrician-gynecologists on intimate partner violence in Flanders, Belgium. BMC Public Health. 2006;6:238.

187. The Commonwealth Fund. 1998 Survey of Women's Health. Available from: http://www.cmwf.org/programs/women/ksc_whsurvey99_332. asp. Accessed 2008 January 15.

188. Kershner M, Anderson JE. Barriers to disclosure of abuse among rural women. Minn Med. 2002;85(3):32-37.

189. McNutt LA, Carlson BE, Gagen D, Winterbauer N. Reproductive violence screening in primary care: perspectives and experiences of patients and battered women. J Am Med Womens Assoc. 1999;54:85-90.

190. Rodriguez MA. Breaking the silence: battered women's perspectives on medical care. Arch Fam Med. 1996;5:153-158.

191. Sleutel MR. Women's experiences of abuse: a review of qualitative research. Issues Ment Health Nurs. 1998;19:525-539.

192. McCord-Duncan EC, Floyd M, Kemp EC, Bailey B, Lang F. Detecting potential intimate partner violence: which approach do women want? Fam Med. 2006;38(6):416-422.

193. Gielen AC, O’Campo PJ, Campbell JC, et al. Women's opinions about domestic violence screening and mandatory reporting. Am J Prev Med. 2000;19(4):279-285.

194. Peralta RL, Fleming MF. Screening for intimate partner violence in a primary care setting: the validity of 'feeling safe at home' and prevalence results. J Am Board Fam Pract. 2003;16:525-532.
195. Sagrestano LM, Rodriguez AC, Carroll D, et al. A comparison of standardized measures of psychosocial variables with single-item screening measures used in an urban obstetric clinic. J Obstet Gynecol Neonatal Nurs. 2002;31(2):147-155.

196. Straus MA. Measuring intrafamily conflict and violence: the Conflict Tactics Scales. J Marriage Fam. 1979;41:75-88.

197. Straus MA, Hamby SL, Boney-McCoy S, Sugarman DB. The revised Conflict Tactics Scales (CTS2): development and preliminary psychometric data. J Fam Issues. 1996;17:283-316.

198. Straus MA. Manual for the Conflict Tactics Scales. Durham, NH: Family Research Laboratory, University of New Hampshire; 1995.

199. Hudson W, McIntosh S. The index of spouse abuse: two quantifiable dimensions. J Marriage Fam. 1981;43:873-888.

200. Marshall L. Development of the severity of violence against women scales. J Fam Violence. 1992; 7:103-121.

201. Yegidis BL. Abuse Risk Inventory Manual. Palo Alto, CA: Consulting Psychologist Press; 1989.

202. Basile KC, Hertz MF, Back SE. Intimate Partner Violence and Sexual Violence Victimization Assessment Instruments for Use in Healthcare Settings: Version 1. Atlanta, GA: Centers for Disease Control and Prevention; 2007.

203. McFarlane J, Parker B, Soetien K, Bullock L. Assessing for abuse during pregnancy: Severity and frequency of injuries and associated entry into prenatal care. JAMA. 1992;267(23):3176-3178.

204. Brown JB, Ryan BL, editors. The Woman Abuse Screening Tool: A Ten-Year Program of Research (CSFM Working Paper Series \#01-1). London, Ontario: The University of Western Ontario, Centre for Studies in Family Medicine; 2001.

205. Sherin KM, Sinacore JM, Li XQ, Zitter RE, Shakil A. HITS: a short domestic violence screening tool for use in a family practice setting. Fam Med. 1998;30:508-512.

206. Shaw D. "Screening" for domestic violence. J Obstet Gynaecol Can. 2003;25(11):918-921.

207. McFarlane JM, Groff JY, O’Brien JA, Watson K. Secondary prevention of intimate partner violence: a randomized controlled trial. Nurs Res. 2006;55:52-61.

208. Garimella RN, Pichta SB, Houseman C, Garzon L. How physicians feel about assisting female victims of intimate-partner violence. Acad Med. 2002;77(12):1262-1265.

209. McFarlane J, Malecha A, Gist J, et al. Increasing safety-promoting behaviors of abused women. Am J Nurs. 2004;104:40-51.

210. Taft AJ, Small R, Hegarty K, Lumley J, Watson LF, Gold L. MOSAIC: protocol and sample description of a cluster randomized trial of mentor mother support to reduce intimate partner violence among pregnant or recent mothers. BMC Public Health. 2009;9:159.

211. Wathen $\mathrm{CN}$, MacMillan HL. Interventions for violence against women. JAMA. 2003;289(5):589-600.

212. Ramsay J, Carter Y, Davidson L, et al. Advocacy interventions to reduce or eliminate violence and promote the physical and psychological well-being of women who experience intimate partner abuse. Cochrane Database Syst Rev. 2009;8(3):CD005043. 


\section{Appendix I \\ Woman Abuse Screening Tool (WAST) from Brown and Ryan 204}

1. In general, how would you describe your relationship? A lot of tension (2) Some tension (1) No tension (0)

2. Do you and your partner work out arguments with... Great Difficulty (2) Some Difficulty (1)

No difficulty $(0)$

3. Do arguments ever result in you feeling put down or bad about yourself?

Often (2) Sometimes (1) Never (0)

4. Do arguments ever result in hitting, kicking, or pushing?

Often (2) Sometimes (1) Never (0)

5. Do you ever feel frightened by what your partner says or does?

Often (2) Sometimes (1) Never (0)

6. Has your partner ever abused you physically?

Often (2) Sometimes (1) Never (0)

7. Has your partner ever abused you emotionally?

Often (2) Sometimes (1) Never (0)

\section{Appendix 2}

HITS Scale: Hurts, Insults, Threatens, Screams from Sherin et al ${ }^{205}$

Please respond to the questions below using the following scale:

$1=$ Never

$2=$ Rarely

$3=$ Sometimes

$4=$ Fairly often

$5=$ Frequently

Since you were pregnant, has a partner or ex-partner... 1. Physically hurt you?

2. Insulted you fairly often?

3. Threatened you?

4. Screamed at you fairly often?

\section{Publish your work in this journal}

The International Journal of Women's Health is an international, peerreviewed open-access journal publishing original research, reports, reviews and commentaries on all aspects of women's healthcare including gynecology, obstetrics, and breast cancer. Subject areas include: Chronic conditions (migraine headaches, arthritis, osteoporosis);
Endocrine and autoimmune syndromes; Sexual and reproductive health; Psychological and psychosocial conditions. The manuscript management system is completely online and includes a very quick and fair peer-review system. Visit http://www.dovepress.com/ testimonials.php to read real quotes from published authors. 